\title{
Geofísica de alta resolução aplicada ao estudo de maciços rochosos, em projeto de construção de túnel.
}

Antonio Flavio Uberti Costa, AFC Geofísica Ltda.

Rodrigo Tusi Costa, AFC Geofísica Ltda.

Lenon Melo Ilha, AFC Geofísica Ltda.

Osmar Wohl, UNISINOS.

\section{Copyright 2014, SBGf - Sociedade Brasileira de Geofísica}

Este texto foi preparado para a apresentação no VI Simpósio Brasileiro de Geofísica, Porto Alegre, 14 a 16 de outubro de 2014. Seu conteúdo foi revisado pelo Comitê Técnico do VI SimBGf, mas não necessariamente representa a opinião da SBGf ou de seus associados. É proibida a reprodução total ou parcial deste material para propósitos comerciais sem prévia autorização da SBGf.

\begin{abstract}
It was performed a high resolution geophysical survey along a stretch in an area of occurrence of crystalline rocks where it was projected to be built a tunnel. It was used the Geolectrical Imaging and Refraction Seismic Tomography techniques. The initial expectation to find at the area was a compact and homogeneous massif rock. However, the geophysical survey results presented an entirely different situation, with three different rock blocks and the presence of many laterals discontinuities, that indicate fracture and fissure zones. The thirteen drillings later executed confirmed the geological situation forecasted by the geophysical survey.
\end{abstract}

\section{Introdução}

Os métodos elétricos e sísmicos aplicados à engenharia vêm se desenvolvendo de forma considerável nos últimos anos, sobretudo na sua capacidade de registro de dados e de processamento dos mesmos. Esse fato vem permitindo que sejam obtidas imagens com alta qualidade e resolução, que refletem cada vez mais a geologia das áreas, com alta precisão. No presente trabalho são apresentadas duas técnicas modernas dos métodos Eletrorresistividade e Sísmica de Refração, com um exemplo de aplicação das mesmas em uma investigação de um maciço rochoso, em área prevista para construção de um túnel. As técnicas aplicadas foram o Imageamento Elétrico Bidimensional - IE2D e a Tomografia por Refração Sísmica - TRS.

\section{Metodologia}

\section{Eletrorresistividade}

- Fundamentação do Uso do Método

O método Eletrorresistividade mede a variação da resistividade elétrica dos solos, sedimentos e rochas, e, a partir destas informações, permite prever a geologia em subsuperfície.

A resistividade elétrica dos materiais rochosos depende basicamente de alguns parâmetros, tais como: porosidade, grau de saturação, resistividade da água subterrânea e fração argilosa.

\section{- A Técnica do Imageamento Elétrico Bidimensional}

A técnica do Imageamento Elétrico Bidimensional mede tanto a variação lateral quanto em profundidade da resistividade elétrica das rochas em subsuperfície, utilizando equipamentos de aquisição automática de dados, com grande número de leituras, permitindo obter-se uma imagem 2D da variação da resistividade elétrica aparente do terreno, com alta resolução.

\section{- A Inversão dos Dados - Modelos 2D de Resistividades Verdadeiras}

Os valores de resistividade aparente são transformados em resistividades verdadeiras através de softwares de inversão, que permitem obter-se modelos de resistividade e profundidade verdadeiras, apresentados em seção 2D (Loke, Barker, 1996). Os modelos obtidos refletem a geologia de subsuperfície de modo mais preciso que as seções de resistividade aparente. O controle de qualidade dos modelos é feito comparandose a seção de resistividades aparentes calculadas para o modelo, com a seção de resistividades aparentes medidas no terreno.

\section{Sísmica de Refração}

Os métodos sísmicos se valem das propriedades elásticas dos solos e rochas para obtenção de informações sobre profundidade e morfologia de alvos em profundidade. Essas propriedades são obtidas indiretamente pelo registro e análise das trajetórias de propagação de ondas sísmicas no meio.

- Tomografia Sísmica

A Tomografia Sísmica é uma técnica similar à tomografia da área médica, em que as ondas são transmitidas através do corpo do paciente em muitas direções (Azwin, Saad, Nordiana, 2013). Na Tomografia Sísmica podem ser usadas as fontes de ondas naturais, como terremotos, ou as fontes artificiais, como, por exemplo, explosivos ou marretas, de modo que, a partir da transmissão de muitas ondas sísmicas, são obtidas imagens de alta resolução do interior da Terra.

Uma das formas mais comuns de se fazer Tomografia Sísmica é através da análise da chegada das ondas $P$ em cada registro sísmico. Usando a distância entre a fonte da onda e o geofone, e o tempo de chegada da onda, é possível determinar a velocidade média de propagação das ondas. Assim, é possível mapear a variação da velocidade, definindo as zonas de altas e de baixas velocidades no meio investigado, sabendo-se que estas dependem do tipo de material atravessado. 
As maiores velocidades correspondem a material mais compacto, tais como rochas cristalinas sãs (ex. granitos ou basaltos maciços não decompostos), e as velocidades menores correspondem a materiais pouco ou não compactos, tais como rochas decompostas (ex. granitos ou basaltos decompostos), sedimentos não consolidados (ex. areias e argilas) e solos.

\section{Resultados}

O levantamento geofísico foi realizado no eixo do túnel, empregando as técnicas IE2D e TRS, com a finalidade de auxiliar no mapeamento geológico de área para construção do túnel.

A técnica IE2D foi aplicada ao longo do eixo do túnel, em uma linha com 3.350 metros, com espaçamento entre eletrodos de 10 metros. A TRS foi aplicada em um trecho ao longo do eixo do túnel, visando o detalhamento de zona de descontinuidades identificadas no IE2D e em sondagens mecânicas. A aquisição dos dados foi feita utilizando espaçamento entre geofones e de pontos de tiro de 5 metros.

No levantamento foram utilizados um resistivímetro SuperSting R8IP, fabricado pela AGI Advanced Geociencies Inc. e um Sismógrafo Geode G24, com 24 canais de geofones, fabricado pela Geometrics Inc.

O resultado do IE2D interpretado está apresentado na Figura 1, juntamente com a localização das sondagens mecânicas realizadas. As variações de resistividade elétrica em profundidade são interpretadas normalmente como mudanças no grau de alteração das rochas, por exemplo: passagem de solo para rocha decomposta, e de rocha decomposta para rocha sã. Por outro lado, as variações laterais de resistividade são interpretadas como contatos entre diferentes litologias ou zonas de falha e/ou fraturas, respectivamente.

$\mathrm{Na}$ seção de IE2D (Figura 1) foram identificados contrastes marcantes de resistividade, com variações tanto em profundidade, quanto laterais. Na seção estão assinalados dois horizontes principais interpretados como relacionados aos contatos entre solo e rocha decomposta e entre rocha decomposta e rocha sã. Lateralmente, observa-se a existência de três blocos com padrões de resistividade distintos. O primeiro, entre as estacas -160 e 1.280, apresenta-se bastante homogêneo em profundidade, sugerindo a ocorrência de rocha sã, sem fraturas e/ou zonas de falha ao longo de todo o bloco. O segundo, entre as estacas $1.280 \mathrm{e}$ 2.940, com um padrão totalmente distinto, bastante heterogêneo, com muitas variações laterais, indicando que neste trecho existem muitas zonas de falha e/ou fraturas, bem como com blocos de rocha sã suspensos em rocha decomposta em profundidade, conforme sugere o padrão observado entre as estacas $1.330 \mathrm{e}$ 1.520. O terceiro bloco observado ocorre a partir da estaca 2.940, mantendo-se até o final da linha, apresenta padrão de resistividades semelhante ao primeiro.

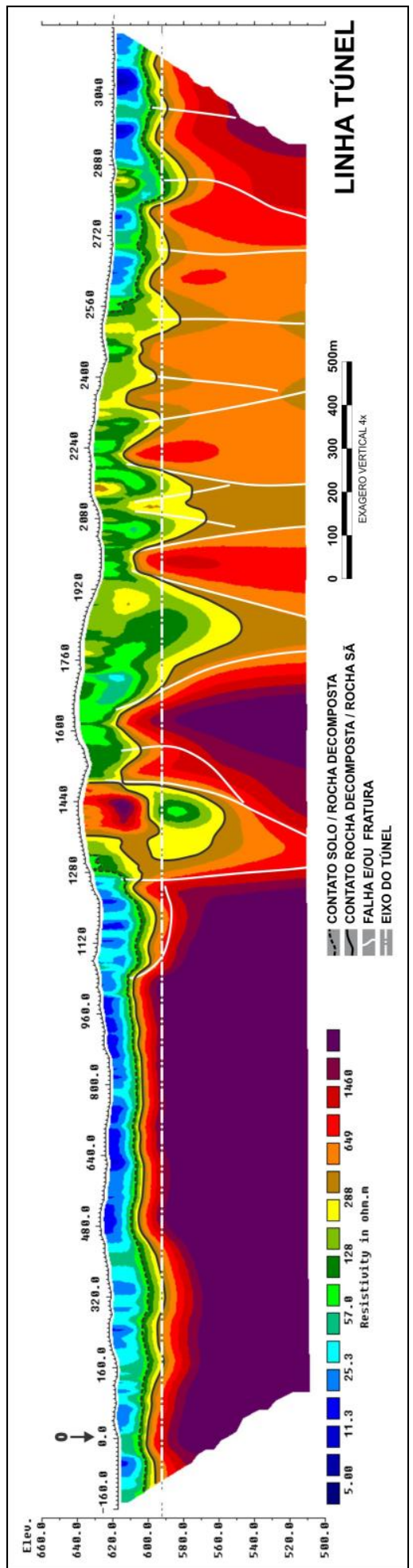

Figura 1 -Resultado do IE2D.

Na Figura 2 está apresentado em detalhe o trecho do bloco 2 da seção de IE2D onde 0 padrão de resistividades invertido sugere a presença de um 
grande bloco rochoso suspenso sobre rochas decompostas em profundidade.

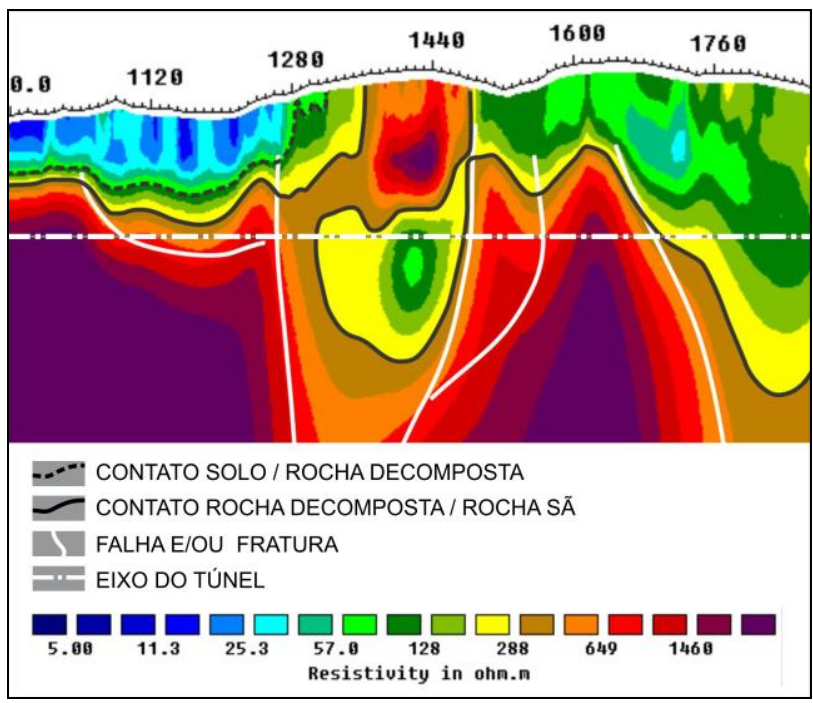

Figura 2 - Resultado do IE2D.

A Figura 3 corresponde ao resultado da TRS, entre as estacas 1.155 e 1.650, em seção de velocidade verdadeira, superposta à seção de IE2D. Os valores de velocidade variam entre $500 \mathrm{~m} / \mathrm{s}$ e $5.500, \mathrm{~m} / \mathrm{s}$, aproximadamente. As velocidades menores que 1.000 $\mathrm{m} / \mathrm{s}$ são interpretadas como correspondentes ao solo e as velocidades maiores que $5.000 \mathrm{~m} / \mathrm{s}$ como correspondentes às rochas sãs. As velocidades entre $1.000 \mathrm{~m} / \mathrm{s}$ e $5.000 \mathrm{~m} / \mathrm{s}$ corresponderiam a rochas decompostas, com diferentes graus de alteração. No trecho entre 1.280 e 1.520 observa-se uma inversão de velocidade em profundidade, sugerindo a presença de um grande bloco de rocha sã neste trecho, sobre camada horizontalizada de rocha decomposta e/ou fraturada em profundidade. Da mesma forma que o IE2D, a seção de TRS também sugere a presença de um grande bloco rochoso suspenso sobre material decomposto neste trecho. Nas estacas 1.270, principalmente, e 1.550, variações laterais de velocidade sugerem a presença de falhas em profundidade.

\section{Correlação Geológico-Geofísica}

A análise dos resultados obtidos nos furos, ao serem correlacionados com as seções de IE2D (Figura 1) e TRS (Figura 3), permite verificar que existe uma correspondência muito boa entre as espessuras definidas nos furos para solos e rocha decomposta e os resultados da geofísica, conforme se pode observar, sobretudo, nos furos SM-301 e SM-304 (Figura 4) e SM310 e SM-311 (Figura 5).

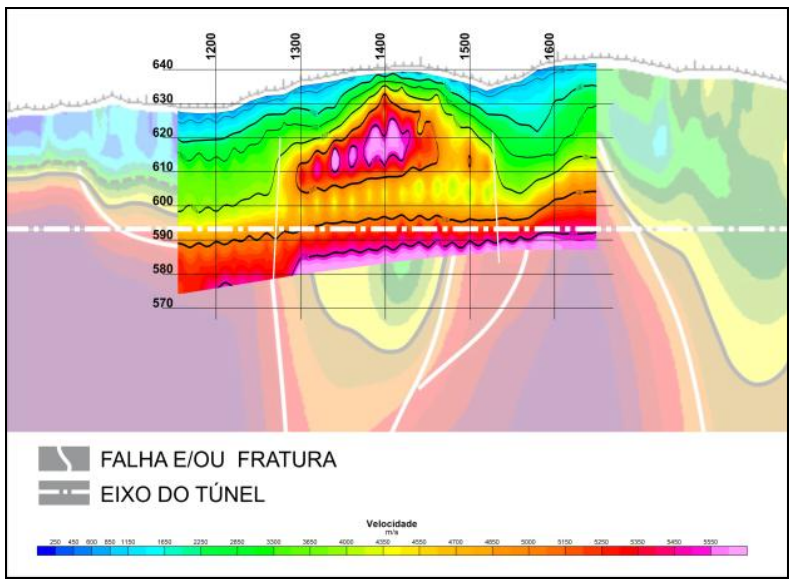

Figura 3-Resultado do TRS.

Além disso, as zonas de rocha fraturada evidenciadas nos furos, da mesma forma, apresentam excelente correlação com os resultados das seções geofísicas. Este é o caso, especialmente, das zonas de fraturas situadas em torno da distância 1280 da seção de IE2D (Figuras 2 e 6) e da TRS (Figura 3). No trecho entre as distâncias 1280 e 1520, onde a geofísica indica a presença de um grande bloco suspenso, e a presença de uma zona com grandes variações laterais de resistividade, os furos realizados confirmam esse padrão de variação lateral do terreno, conforme se pode observar na Figura 6, na descrição dos furos SM-530, SM-307, SM-531 e SM-532.

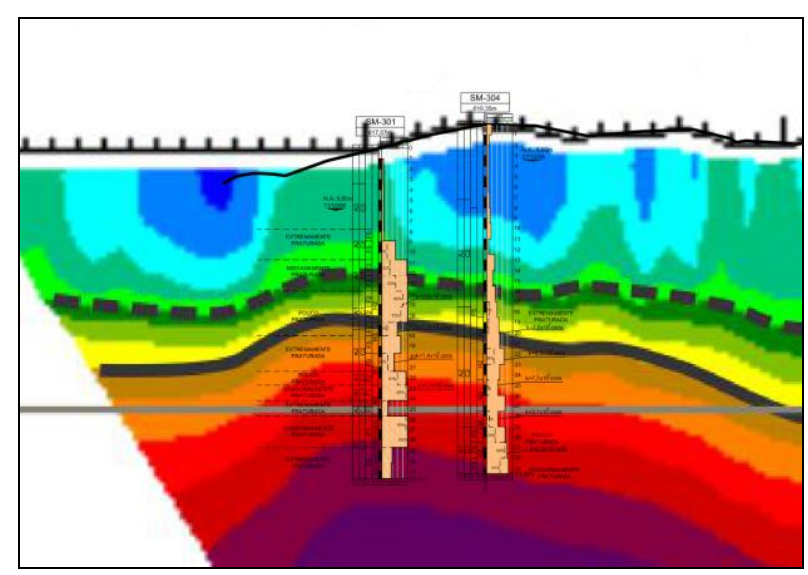

Figura 4 - Furos SM-301 e SM-304

\section{Discussão e Conclusões}

As técnicas aplicadas forneceram imagens de subsuperfície de variação da resistividade e da velocidade das ondas $P$, com alta precisão, permitindo estimar com segurança as espessuras de solo e rocha decomposta, bem como o topo rochoso ao longo do perfil, além de detectar as descontinuidades laterais indicativas de zonas de falhas. $O$ detalhamento através 
da Tomografia de Refração Sísmica de um trecho em que o Imageamento Elétrico sugeria a existência de um grande bloco suspenso de rocha sã em meio alterado, mostrou-se bastante útil, com a sísmica confirmando, de certa forma, a presença do bloco suspenso a partir da definição de uma inversão de velocidade das ondas $P$ com a profundidade.

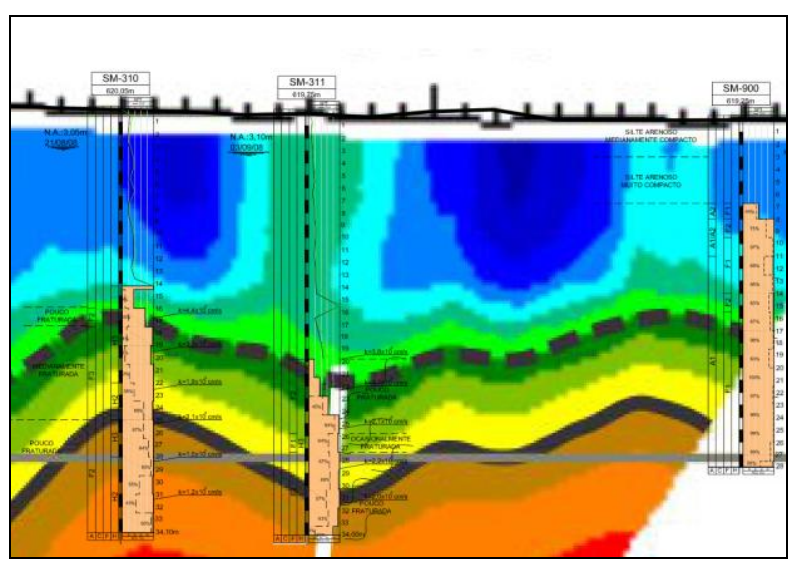

Figura 5 - Furos SM-310 e SM-311

A expectativa inicial, anterior à investigação geofísica, era a de ser encontrado, no trecho projetado para a construção do túnel, um maciço de rochas cristalinas compactas. A geofísica mostrou uma realidade bastante distinta, com muitas zonas de fraturas ocorrendo em vários trechos. As sondagens mecânicas realizadas em zonas anômalas, indicadas pela geofísica, confirmaram as previsões desta.

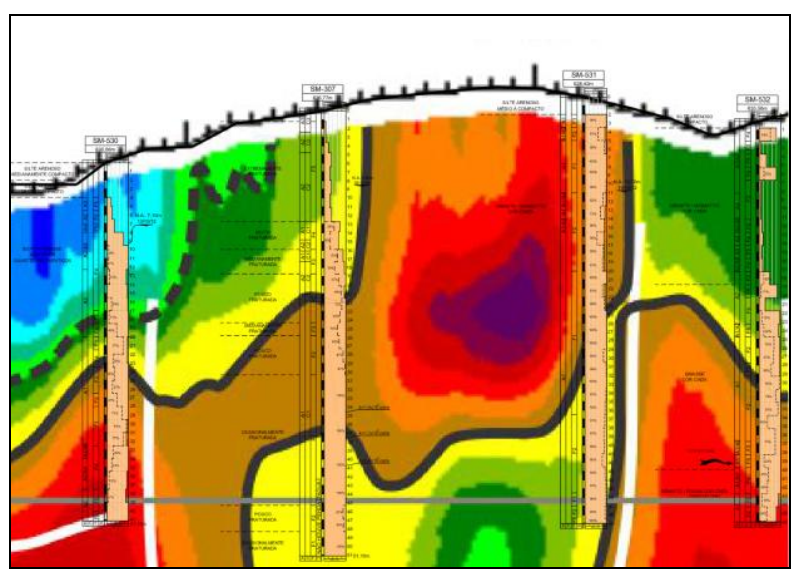

Figura 6 - Furos SM-530, SM-307, SM-531 e SM-532

\section{Agradecimentos}

Agradecemos à ECOPLAN ENGENHARIA pela contribuição, fornecendo os dados das sondagens mecânicas.

\section{Referências}

Azwin, I. N., Saad, R. and Nordiana, M., 2013. Apllying the Seismic Refraction Tomography for Site Characterization. In: Procedia APCBEE. ELSEVIER, Dubae, UAE: $227-231$.

Loke, M. H. and Barker, R. D., 1996. Rapid LeastSquares Inverson of Apparent Resistivity Pseudosections by a Quasi-Newton Method. Geophysical Prospecting, 44: 131-152. 